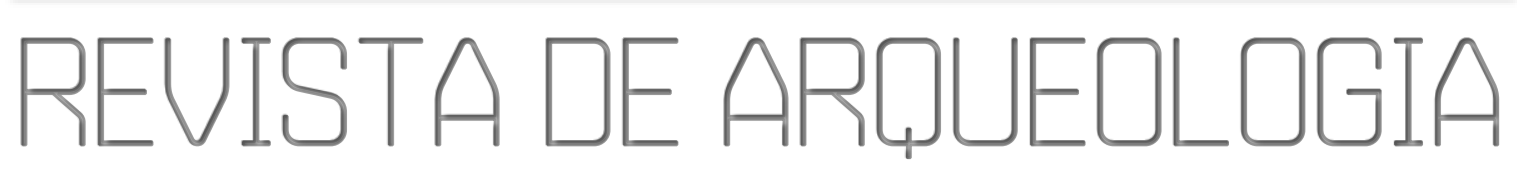

Volume 34 No.1 Janeiro-Abril 2021

\title{
REVISITANDO ANÁLISES DE CERÂMICAS NO SUL E SUDESTE BRASILEIRO
}

Glauco Constantino Perez*, Renan Pezzi Rasteiro**,

Fabiana Terhaag Merencio***, Isabela da Silva Müller**

\section{RESUMO}

Este artigo revisita estudos específicos realizados nos últimos anos, selecionados com o intuito de compreender como os pesquisadores realizaram as análises em cerâmica arqueológica brasileira, sendo este um dos principais marcadores culturais conhecidos na disciplina. Para tanto, realizamos um levantamento bibliográfico com intuito de reunir trabalhos realizados nessa temática. $\mathrm{O}$ levantamento identificou a autoria e os métodos da análise cerâmica aplicados. Isso nos permitiu rastrear quais métodos foram utilizados para a análise de cerâmica e, por sua vez, o viés interpretativo ligado aos trabalhos. Esperamos que a partir deste artigo a comunidade científica se atente para os métodos aplicados à pesquisa, com o intuito de aprofundar as análises e permitir novos tipos de inferências sobre as populações ceramistas.

Palavras-chave: Arqueologia Brasileira; cerâmica arqueológica; métodos de análise.

\footnotetext{
* Doutor pelo Programa de Pós-graduação em Arqueologia (MAE/USP). Pós-doutorando no Instituto de Biociências e pesquisador colaborador do Laboratório de Estudos Evolutivos Humanos (LEEH/IB). Rua do Matao Tv. 14. Cidade Universitária, Universidade de São Paulo - USP/SP. CEP. 05508-090. E-mail: glauco1113@usp.br. ORCID: https://orcid.org/0000-0002-1472-3360.

** Doutorando do Programa de Pós-graduação em Arqueologia (MAE/USP) E-mail: rpezzir@usp.br. ORCID: https://orcid.org/0000-0002-2781-4114.

*** Doutoranda do Programa de Pós-graduação em Arqueologia (MAE/USP).

E-mail: f.terhaag@gmail.com. ORCID: https://orcid.org/0000-0003-4848-9194.

**** Mestre Programa de Pós-graduação em Arqueologia (MAE/USP).

E-mail: isabeladsmuller@gmail.com. ORCID: https://orcid.org/0000-0002-9658-501X.
} 


\section{A REVIEW OF CERAMIC ANALYSIS IN SOUTHERN AND SOUTHEASTERN}

\section{BRAZIL}

\section{ABSTRACT}

This article revisits specific studies carried out in the last years, selected in order to understand how researchers analyzed Brazilian archaeological ceramics, which is one of the main cultural markers known in the discipline. To this, we carried out a bibliographic survey in order to gather works on this theme. The survey identified the authorship and the methods of ceramic analysis applied. This allowed us to track which methods were used for the analysis and the interpretative bias linked to the works. We hope that from this article on, the scientific community will pay attention to the methods applied to research, in order to thoroughly analyze and allow new types of inferences about the ceramist populations.

Keywords: Brazilian Archaeology; archaeological ceramics; analysis methods.

\section{REVISANDO EL ANÁLISIS CERÁMICO EN EL SUR Y SURESTE DE BRASIL}

\section{RESUMEN}

Este artículo revisa estudios específicos realizados en los últimos años, seleccionados para comprender cómo los investigadores realizaron los análisis sobre la cerámica arqueológica brasileña, que es uno de los principales marcadores culturales conocidos en la disciplina. Para ello, realizamos un levantamiento bibliográfico con el objeto de recopilar obras sobre este tema. El relevamiento identificó la autoría y los métodos de análisis cerámico aplicados, lo que permitió rastrear qué métodos se utilizaron para el análisis de la cerámica y, a su vez, el sesgo interpretativo vinculado a los trabajos. Esperamos que a partir de este artículo la comunidad científica preste atención a los métodos aplicados a la investigación, con el fin de profundizar los análisis y permitir nuevos tipos de inferencias sobre las poblaciones ceramistas.

Palabras clave: Arqueología Brasileña; cerámica arqueológica; métodos de análisis. 


\section{INTRODUÇÃO}

Neste artigo pretendemos apresentar como as análises de cerâmica têm sido feitas nas últimas décadas. $\mathrm{O}$ mote gerador partiu das observações de teses e dissertações recentes, onde foi constatado que raramente os autores deixam claros os motivos e a necessidade que os levaram a selecionar os atributos avaliados nas análises do material em detrimento de outros. Este artigo descortina a utilização de determinados roteiros de análise e consequente seleção automática de atributos, bem como os referenciais teóricos empregados, como a cadeia comportamental, a cadeia operatória, a tipologia, entre outros. Nesse sentido, temos a oportunidade de nos questionar sobre a diferença em termos interpretativos ao adotar um referencial teórico e qual a relação entre o método de análise e a teoria aplicada nesses trabalhos.

A partir da observação de 43 trabalhos acadêmicos, apresentamos um panorama de como as análises de cerâmica foram realizadas, sendo: 20 para o estado de São Paulo, 14 para o estado do Paraná e nove para o estado de Santa Catarina. Nos atentando que o marcador cerâmico é fundamental na arqueologia brasileira, já que a partir dele se estruturaram as tradições arqueológicas definidas pelo Programa Nacional de Pesquisas Arqueológicas (PRONAPA) entre as décadas de 1960 e 1970, utilizadas na disciplina até hoje, bem como mapear as respectivas influências regionais/locais. Neste trabalho não proporemos críticas ao método pronapiano, pois foge ao escopo do trabalho, mas a proposta é identificar como a arqueologia do sul e sudeste do Brasil utiliza de seus termos em pesquisas atuais. Ainda destacamos que o uso do termo "tradição" foi adotado neste artigo com o intuito de facilitar a compreensão dos leitores, pois é um termo amplamente difundido entre os pesquisadores da área, e desse modo, não entramos no mérito se há ou não unanimidade no uso, sua naturalização ou construções teóricas que foram utilizadas no período da sua cunhagem.

É fundamental deixar claro ainda, que não pretendemos realizar um levantamento exaustivo e que demos preferência às publicações que pudessem trazer informações a respeito da análise em cerâmica, prezando para a seleção de trabalhos acadêmicos, principalmente teses, dissertações e artigos científicos, e que estivessem com acesso facilitado (bibliotecas online e/ou digitalizadas), dadas as restrições enfrentadas ultimamente no acesso aos trabalhos depositados em bibliotecas físicas.

O artigo está dividido em três seções específicas por estado, onde são apresentados os principais trabalhos que pudessem dar conta de como as análises cerâmicas foram conduzidas. Para o estado de São Paulo, focamos nos dados encontrados no Museu de Arqueologia e Etnologia (MAE/USP); no estado do Paraná tivemos como ponto observador a Universidade Federal do Paraná, em especial o Centro de Estudos e Pesquisas Arqueológicas (CEPA/UFPR), e para o estado de Santa Catarina, consultamos os principais núcleos de pesquisas e de memória, citados no decorrer do texto.

O levantamento focou nos últimos 11 anos, entre 2007 e 2018, dentro de Universidades Públicas. No entanto, também foram incluídos, de forma sintetizada os trabalhos de autoras pioneiras, como Luciana Pallestrini, Silvia Maranca e Erika Marion Robrahn-González, do estado de São Paulo, devido a importância para a compreensão no referencial analítico desse estado. Para o estado do Paraná, iniciamos com as publicações a partir dos anos de 1950, dada a fundação do CEPA/UFPR, e em Santa Cataria, as descrições se iniciam com os trabalhos de Piazza nos anos de 1960, junto ao grupo de pesquisadores que estiveram à frente do PRONAPA. Esse recorte visou a compreensão sobre como os métodos de análise cerâmica foram aplicados nas pesquisas arqueológicas realizadas nesses estados, e não teve o intuito de generalizar o quadro, mas sim de refletir e retomar debates importantes para o desenvolvimento da pequisa no Brasil. 
Quanto aos termos de classificação utilizados na arqueologia brasileira, Araujo (2019) acredita que parece haver uma certa confusão entre "comparabilidade" e "normatização tipológica”. O autor utiliza de exemplos da indústria lítica para explicar tal confusão e complementa que se os pesquisadores não começarem a utilizar os mesmos termos para designar as mesmas peças, os problemas começarão a se multiplicar dentro do nosso país, considerando a grande variedade de atributos avaliados em diferentes pesquisas e a quantidade de pesquisadores ativos no Brasil. Em relação aos estudos de cerâmica, tais problemas também acontecem, haja vista as confusões geradas para a aplicação de termos simples como a barbotina, o engobo, o banho, ou mesmo todas as indefinições aplicadas à caracterização de bordas com seus tipos, angulações, inclinações e espessuras, também em relação ao corpo da vasilha e aos tipos de lábios analisados. Essas imprecisões são comuns aos pesquisadores que tem a cerâmica como objeto de estudo e, mesmo os mais próximos da temática, têm dificuldade em definir tais termos baseando-se apenas em trabalhos como de La Salvia e Brochado (1989). Tal situação é mais aparente em pesquisas recentes que não têm o conhecimento empírico trazidos pela prática da olaria e/ou da análise de acervos cerâmicos. Quando se fala em análise de material cerâmico, a principal referência que se tem é justamente o celebre trabalho de La Salvia e Brochado (1989), que serve de base metodológica e classificatória para muitos pesquisadores e, não por menos, talvez seja uma das poucas obras de maior completude sobre cerâmica que temos acesso em língua portuguesa sobre tecnologia, estilo e morfologia. No entanto, o trabalho de La Salva e Brochado (1989) tem sido aplicado de forma indiscriminada, como por exemplo, a utilização de parâmetros estilísticos para cerâmica que não seja a considerada Guarani, como alguns trabalhos realizados com cerâmica histórica ou de outros grupos culturais.

Dessa forma, Araujo (2019) sugere que a elaboração e utilização de um glossário comum poderá abarcar as tentativas de uniformização de rótulos para os tipos analisados entre arqueólogos. Além de uma unificação dos métodos de classificação e análise de materiais arqueológicos, o autor exalta que a normatização da descrição dos atributos seria louvável, embora acredite que apenas isso não seria a solução para que possamos unificar as nossas análises, já

(...) que não interessa o nome dado a uma peça, não interessa o rótulo aplicado a um determinado tipo: toda a comparabilidade entre peças, indústrias ou componentes de sítios arqueológicos reside na definição da classe por meio da estipulação das condições necessárias e suficientes para que um determinado objeto seja a ela designado (ARAUJO, 2019, p. 238-239).

Nesse sentido, é indiscutível que as análises de materiais arqueológicos precisem apresentar descrições claras e que são possíveis apenas se as unidades classificatórias forem definidas, permitindo assim, correlações com outros estudos. Araujo (2019) ressalta, ainda, que é imperativo deixar claro quais são os atributos utilizados para as análises arqueológicas e, sobretudo, os porquês da adoção de tais métodos de análise e de classificação.

Esse tipo de reflexão tem se expandido pelo mundo e, como destacam Riede et al. (2020), essa atenção dada ao método utilizado nas análises e suas classificações é fundamental para a construção de definições robustas das unidades taxonômicas, para que os arqueólogos possam padronizar suas unidades analíticas, que possuem implicações diretas nas discussões que permitam identificar, por exemplo, as mudanças culturais e comportamentais no espaço e no tempo.

Para Riede et al. (2020), a definição de unidade taxonômica depende de critérios consistentes para sua definição e delimitação e, além disso, acordos mútuos entre os pesquisadores sobre os significados dentro dos sistemas taxonômicos, bem como noções 
antropológicas, étnicas ou linguísticas bem definidas, já que as mesmas são fundamentais para que as unidades classificatórias arqueológicas possam ser operacionalizadas. Nesse sentido, os autores acreditam que apenas com esses requisitos básicos é que pesquisas comparativas e cumulativas possam acontecer em escalas regionais. Diante disso, este artigo tem o intuito de analisar alguns trabalhos arqueológicos que envolvam análise de cerâmica e que apresentem os critérios analíticos, quiçá classificatórios, e que possibilitem compreender os métodos utilizados neles. Isso permitiu estabelecer os principais vieses das diferentes abordagens classificatórias e, a partir daí, eventualmente permitirá alguma unificação básica em termos analíticos.

Apenas observando questões como o que e como as análises têm sido conduzidas é que poderemos ter uma visão, mesmo que parcial, das pesquisas realizadas pelo Brasil e, como afirma Corrêa (2014), nos obrigando a refletir sobre o nosso papel para tentar mudar uma situação, nem que seja organizando nossa própria "papelada", realizando, nesse sentido, uma autorreflexão do fazer arqueológico e unificação de formas de análises sugerida por Araujo (2019).

\section{O ESTADO DE SÃO PAULO}

A fim de contextualizar, as primeiras pesquisas arqueológicas sistemáticas com material cerâmico no estado de São Paulo foram realizadas no final da década de 1960, com os estudos desenvolvidos por Luciana Pallestrini, pesquisadora do Museu Paulista, na bacia do rio Paranapanema (PALLESTRINI, 1968/1969). O Projeto Paranapanema, como foi denominado, tinha o objetivo de compreender as antigas ocupações humanas ao longo da margem paulista do Rio Paranapanema (MORAIS, 1981; MORAIS et al., 2000). A autora, tendo sido orientada por André Leroi-Gourhan em seu doutorado, trouxe em seu método analítico a influência de uma arqueologia etnográfica estruturalista francesa, que tinha entre suas questões a compreensão das etapas de produção dos recipientes, selecionando atributos dentro da ideia de uma cadeia operatória (PALLESTRINI, 1968/1969).

Ainda na mesma década de 1960, Silvia Maranca realizou diversas pesquisas no interior do estado de São Paulo, como membro do PRONAPA, cujos relatórios publicados tinham como enfoque a análise de sítios cerâmicos (MARANCA, 1969; MARANCA et al., 1994). Seguindo as diretrizes do programa, as análises cerâmicas obedeciam aos protocolos que tinham como principal referência o método desenvolvido por James Ford (1962), a seriação por frequência, que é uma técnica para ordenação cronológica de coleções de tipos presumivelmente históricos, de tal forma que cada tipo tem uma distribuição contínua e de frequência unimodal. A ordenação dos fenômenos baseia-se nas frequências de tipos (O'BRIEN; LYMAN, 2000).

Nos trabalhos de Pallestrini (1968/1969) e Maranca (1969), notam-se duas frentes de pesquisa com influências diferentes e que viriam a alimentar o debate acerca dos métodos de análises cerâmica no Brasil. Por um lado, uma análise cujo método procurava contextualizar a cadeia operatória dos fragmentos analisados, focando nas etapas de produção dos recipientes, e por outro, uma análise por seriação, influenciada pelo modelo de Ford (1962), trazido pelos pesquisadores Betty J. Meggers e Clifford Evans na década de 1960. Essas influências estrangeiras são elemento fundamental em toda arqueologia brasileira e em parte explicitam como as teorias disseminadas devem ser compreendidas dentro dos contextos históricos específicos, a partir dos quais as pesquisas subsequentes foram construídas. Como sugere Barreto:

Para se avaliar as orientações teórico-metodológicas da arqueologia contemporânea no Brasil resta-nos ainda rever de forma sistemática a trajetória de escolha, aprendizado, e adaptação de teorias e práticas arqueológicas provenientes de 
contextos diversos ao caso nacional por parte da comunidade arqueológica brasileira.

(BARRETO, 1999, p. 211).

Ainda em tempo, não se pode deixar de lado a influência e importância das iniciativas trazidas por Erika Marion Robrahn-González (1989, 1996, 1998), sendo pioneira no estado de São Paulo a fundamentar teoricamente seu método de pesquisa usado por muitos posteriormente (ver MORAES, 2007; WICHERS, 2012), sendo um exemplo didático de rigor epistemológico. Além disso, foram de fundamental importância trabalhos como de Faccio $(1998,2011)$, responsável pela formação de diversos pesquisadores que atuaram nas regiões norte, sul e oeste do de São Paulo. Talvez a dificuldade de se construir um paradigma teórico-metodológico brasileiro se deva pela própria forma como os grandes centros de pesquisa se formaram, onde, em um primeiro olhar, não parece ter havido uma preocupação com aspectos teóricos e de interpretação dos dados, mas sim, com a ideia de resgatar, preservar e registrar os vestígios arqueológicos e , aprender métodos de classificação e de documentação.

Essa afirmação se dá a partir do próprio processo de colonização que sofremos, que trouxe em seu arcabouço uma europeização do pensamento científico, influenciando diretamente na formação da arqueologia no país, que se voltou para a construção de histórias culturais, fundamentada em uma concepção normativa de cultura. Com isso, os primeiros pesquisadores se concentraram na classificação de artefatos e sítios arqueológicos, organizando-os no tempo e espaço, buscando identificar elementos diagnósticos e construindo tipologias (LIMA, 2000). Dessa forma, a arqueologia brasileira em sua infância se aproximava muito mais da história natural do que da história ou antropologia, dado problemático em um país onde a arqueologia estuda, na maior parte do tempo, o passado de povos indígenas (BARRETO, 1999).

Dentro dessa situação, ao analisarmos algumas pesquisas no âmbito das universidades, notamos alguns movimentos que têm retomado antigas ideias e trazido novas perspectivas teóricas, que, em alguns casos ainda são incipientes, e em outros tem mostrado grande acolhida pelos arqueólogos brasileiros.

Fazendo um salto temporal, e focando o período específico compreendido por este artigo, nas primeiras décadas dos anos 2000, autores buscaram propostas teóricas que permitissem ampliar as interpretações sobre a cerâmica. O uso de dados provenientes de outras disciplinas demonstrou-se como uma tentativa de reaproximação da arqueologia com outras disciplinas das ciências humanas, biológicas e exatas, principalmente a antropologia e geologia que, por si só já apresentavam um avanço teórico muito mais proeminente. A reaproximação da arqueologia com a antropologia se mostrou recorrente com a utilização de dados etnográficos, etnohistóricos e linguísticos por parte dos arqueólogos dentro do contexto paulista (RODRIGUES, 2007; MORAES, 2007; SALLUM, 2011; PEREIRA, 2012; LOPES, 2014; RIBEIRO, 2017; CRISTANTE, 2017). Outros trabalhos também têm focado na relação do homem com a paisagem, em uma evidente aproximação da arqueologia com a ciências da terra, buscando revelar a distribuição espacial dos contextos arqueológicos e o modo como os povos indígenas, objetos e a paisagem interagiam entre si (CABRERA, 2009; 2015; SALLUM, 2011; PEREIRA, 2012; LOPES, 2014; DAVES, 2018; LIMA, 2018).

Em relação aos métodos o que pode se notar, nas pesquisas acadêmicas com foco no material cerâmico no estado de São Paulo, é a recorrência dos conceitos de cadeia operatória, tecnologia e estilo. O conceito de cadeia operatória foi utilizado por Bélo (2007), Franco (2007), Moraes (2007), Rodrigues (2007), Cabrera (2009 2015), Sallum (2011, 2018). Pereira (2012), Lopes (2014), Cristante (2017), Ribeiro (2017), Zago (2017), Daves (2018), Lima (2018). Com descreve Galhardo (2015), o conceito de cadeia operatória foi cunhado por Mauss no início do século XX dentro da antropologia, e 
Leroi-Gourhan posteriormente adotou tais definições. O conceito busca dar sentido ao objeto, na medida em que objetiva desvendar todo seu histórico em uma série de operações que transformam a matéria-prima em um produto, quer seja um objeto de consumo ou um utensílio (GALHARDO, 2015).

Quando observamos o processo de análise das pesquisas, em relação às escolhas tecno-tipológicas contamos em São Paulo com os trabalhos de Belo (2007), Moraes (2007), Rodrigues (2007), Cabrera (2009, 2015), Sallum (2011, 2018), Pereira (2012), Lopes (2014), Perrota (2015), Cristante (2017), Ribeiro (2017), Zago (2017), Baco (2018) e Lima (2018), que selecionaram atributos como o tratamento de superfície, a técnica de manufatura, a decoração e o tipo de borda e de queima.

A escolha desse tipo de análise tecnológica é conhecida na área como antropologia da tecnologia, e busca entender em que medida as escolhas do artesã(ão) são motivadas por aspectos de necessidade e recorrência de material, tentando compreender a arbitrariedade das escolhas tecnológicas e seus respectivos significados dentro do contexto cultural de determinado grupo (SILVA, 2000, p. 24). Nesse sentido, observamos novamente uma reaproximação da arqueologia com a antropologia, a partir da contribuição de formulações de explicações e compreensões dos povos indígenas pretéritos ocupantes do atual estado de São Paulo.

A utilização de métodos de análise físico-químicas também aparece nas pesquisas de Bélo (2007) e Sallum (2011). Ambas utilizaram a técnica de Fluorescência de Raios X por dispersão em Energia (EDXRF), sendo que Bélo (2007) aplicou ainda a Microscopia Óptica de Luz Transmitida. Tal aproximação com as ciências exatas, aparece de maneira menos incipiente nas pesquisas sobre cerâmica realizadas em São Paulo, como pode-se observar, no entanto os resultados obtidos apresentam consonância com os dados etnográficos e históricos.

De maneira geral, a discussão sobre a escolha dos atributos analisados pouco aparece nos trabalhos levantados e o que se observou foi que há visões divergentes entre os pesquisadores acerca das unidades analíticas, principalmente em atributos ligados ao estilo e função, o que não acontece quando se utiliza de dados trazidos de áreas das exatas, por exemplo, que existe a tentativa da explicação do funcionamento do método aplicado. As definições dos elementos a serem analisados não parecem dialogar com as perspectivas teóricas e as perguntas levantadas pelos pesquisadores. Esse tipo de análise nos distancia das possibilidades de uma normatização dessas unidades analíticas. Nas Tabelas 1 e 2 apresentamos os autores supracitados com suas contribuições analíticas especificadas dentro de um parâmetro que buscou unificar e padronizar todos os trabalhos observados.

Entretanto cabe refletir que se os estudos em arqueologia brasileira almejam progredir em termos interpretativos e metodológico devemos pensar em um denominador comum para as análises realizadas, com uma unidade de tipos de registro e condições de pesquisa no Brasil, fatores que unificariam os inúmeros arqueólogos do país. Tal proposta têm sido retomada por Araujo (2019) e Riede et al. (2020) não no sentido de restringir os estudos arqueológicos, e compreendemos que uma padronização dos atributos observados pelos pesquisadores possibilitará a correlação e diálogo entre diferentes trabalhos.

\section{O ESTADO DO PARANÁ}

As primeiras análises de vestígios cerâmicos no Paraná estão relacionadas com as atividades do CEPA/UFPR sob a coordenação de José Loureiro Fernandes. Fundado em 1956, o CEPA/UFPR foi central na organização de diferentes cursos que auxiliaram na formação dos primeiros arqueólogos do país. Destaca-se aqui o seminário ministrado em 
1964 por Betty Meggers e Clifford Evans, que apresentou os procedimentos analíticos relativos à classificação e interpretação dos vestígios cerâmicos com o intuito de mapear a distribuição espaço-temporal e variabilidade dos conjuntos para a reconstrução do "desenvolvimento cultural pré-histórico ao longo da faixa costeira" (MEGGERS, 2007, p. 33).

Para estabelecer as cronologias relativas, foram enfatizados os métodos de classificação pautados na identificação de tipos (definidos pela correlação de atributos), como a taxonomia e os procedimentos de quantificação e seriação formulados por Ford (MEGGERS; EVANS, 1970; MEGGERS, 2007). Como resultado, foram publicados uma terminologia comum à área (CHMYZ, 1966) e um manual de análise cerâmica (MEGGERS; EVANS, 1970), cujo principal método foi a classificação hierárquica de tipos, considerando as variações temporais, espaciais e formais. $\mathrm{O}$ primeiro nível de análise era a classificação dos fragmentos a partir do tratamento de superfície, decorados e não-decorados (simples), e nos demais níveis eram avaliados atributos tecnológicos, como o antiplástico/tempero, a queima, entre outros, e em caráter descritivo dos tipos identificados.

O método de classificação hierárquica foi aplicado nos trabalhos desenvolvidos pelo CEPA/UFPR no período analisado (CHMYZ et al., 2008; 2009) e na dissertação de Volcov (2011). Nesses trabalhos verificou-se a seleção do acabamento de superfície e antiplástico para o primeiro nível hierárquico e os demais atributos de análise selecionados apresentam relação com a caracterização tecno-tipológica, como a técnica de produção, a espessura, o tipo de queima, as dimensões do vasilhame, o tipo de antiplástico, a coloração, além da reconstrução gráfica de bordas e bases, utilizadas na classificação morfológica.

Com uma abordagem semelhante, Schmitz e Rogge (2008) apresentaram os resultados da análise cerâmica a partir da identificação de seis conjuntos definidos com base em aspectos morfológicos e funcionais, seguida da caracterização dos atributos tecnológicos identificados em cada conjunto como a espessura, o diâmetro das bordas, a pasta e o antiplástico.

Os trabalhos realizados por Parellada (2008a, 2008b, 2018), cuja trajetória de pesquisa foi iniciada no CEPA/UFPR, também apresentam elementos da classificação hierárquica, observada na definição de classes a partir do tratamento de superfície, entre simples e decorados (PARELLADA, 2008a, p. 104). Contudo, a pesquisadora avançou em termos de reflexão do método de análise ao incluir elementos da caracterização tecnológica, de acordo com os manuais de Shepard (1956) e Rye (1981). Shepard (1956) considerou a classificação perigosa devido ao uso de critérios subjetivos na definição dos tipos e enfatizou a necessidade de se aprofundar o conhecimento sobre as técnicas de produção a partir de estudos etnográficos e de experimentação, tendo como objetivo a identificação adequada da variabilidade tecnológica e das escolhas efetuadas pelo agente produtor. Já Rye (1981) apresentou a ordenação dos atributos tecnológicos em uma perspectiva da sequência de produção, desde a seleção da matéria-prima, perpassando pelas técnicas de produção, aspectos de distribuição, uso, quebra e de reciclagem, e nesse sentido, a proposta de Rye é semelhante à concepção de cadeia operatória. Parellada (2008a, 2008b) também incorporou dados etnográficos sobre a produção cerâmica de grupos Kaingang e Xokleng e realizou estudos arqueométricos para verificação dos padrões de fraturas dos fragmentos a partir de radiografias, além de outras técnicas, como a Fluorescência por Raio-X e espectroscopia Raman, em parceria com o Laboratório de Física Nuclear da Universidade Estadual de Londrina (LFNA/UEL) (PARELLADA, 2018). 
No trabalho de Hepp (2012), a seleção dos atributos de análise contemplou as diferentes etapas de produção da cerâmica, seguindo a definição da cadeia comportamental de Schiffer (1972), onde são verificadas etapas não lineares de procura, manufatura, uso, reciclagem, descarte e refugo. Os atributos analisados foram divididos em três grupos: matéria-prima (tipo e frequência do antiplástico), manufatura (técnica de produção, tratamento de superfície, técnica de decoração), e função (forma, diâmetro e ângulo da borda, marcas de uso, estado de preservação) interpretada em conjunto com os grupos funcionais definidos em trabalhos etnohistóricos, como de La Salvia e Brochado (1989), Brochado et al. (1990) e Brochado e Monticelli (1994). Outras referências citadas por Hepp para a análise são Chmyz (1976) e Orton et al. (1997). A análise também buscou a formação de conjuntos de fragmentos pertencentes a uma mesma vasilha e a definição qualitativa do número mínimo de vasilhames, utilizada na arqueologia histórica, como definido por Rice (1987, p. 292-293) e Voss e Allen (2010).

A análise de acervos de museus regionais, mesmo em coleções que apresentam poucos fragmentos foi explorada por Menegusso (2017), com a seleção de atributos de análise pautada em La Salvia e Brochado (1989), Chmyz (1976) e Shepard (1956), sendo avaliados sobretudo aspectos tecnológicos e morfológicos.

Em uma linha de análise distinta das mencionadas até aqui, encontra-se os trabalhos de Perez (2010a, 2010b, 2010c) e Perez e Mota (2011), que buscaram caracterizar os grafismos da cerâmica Guarani. Para tal, os autores partiram na noção de etnoarte de Vidal (1992) e da proposta de análise La Salvia e Brochado (1989) para definição dos grupos funcionais e modelo descritivo dos motivos dos grafismos (tipo e largura da linha, tracejado, posição do grafismo etc.), modo da aplicação e espessura da faixa do grafismo.

Por fim, Apolloni (2018) recentemente publicou um artigo em que sintetiza os estudos arqueométricos pioneiros realizados pelo LFNA-UEL com a aplicação de métodos como densitometria (transmissão e espalhamento de raios gama, radiografia digital e micro tomografia com raios-X), composição química elementar (Fluorescência de Raios X [EDXRF, PXRF, TXRF]), e Composição Molecular por Espectroscopia Raman. Esse método é uma aproximação da arqueologia aos métodos físicos e químicos analisando as coleções etnográficas (Kaingang) e arqueológicas (Guarani), provenientes do norte do Paraná, além de conjuntos de outros estados, como Maranhão e Pará. As análises foram realizadas para caracterização da pasta, como a homogeneidade e o antiplástico, além de identificar os pigmentos empregados no tratamento de superfície.

\section{O ESTADO DE SANTA CATARINA}

O estado de Santa Catarina conta com instituições cujas linhas de pesquisa são interdisciplinares em arqueologia, oferecendo a oportunidade de pesquisa em laboratórios como: o Centro de Memória do Oeste de Santa Catarina (CEOM/UNOCHAPECÓ), a Universidade da Região de Joinville (UNIVILLE), o Museu Arqueológico de Sambaqui de Joinville (MASJ), o Laboratório de Arqueologia Pedro Ignácio Schmitz da Universidade do Extremo Sul Catarinense (LAPIS/UNESC), o Grupo de Pesquisa em Educação Patrimonial e Arqueologia da Universidade do Sul de Santa Catarina (GRUPEP/UNISUL), o Laboratório de Arqueologia do Museu de Arqueologia e Etnologia Professor Oswaldo Rodrigues Cabral da Universidade Federal de Santa Catarina (MArquE/UFSC) e o Laboratório de Estudos Interdisciplinares em Arqueologia da Universidade Federal de Santa Catarina (LEIA/UFSC).

Na década de 1960, Walter Fernando Piazza e o padre jesuíta João Alfredo Rohr foram pioneiros nas pesquisas arqueológicas em Santa Catarina. Piazza foi representante do PRONAPA no estado e aplicou o método definido pelo programa a partir das denominações de tradições e fases (PIAZZA, 1967). O autor teve a oportunidade de 
realizar a análise de material cerâmico tendo como fonte os trabalhos de Ford (1962), Meggers e Evans (1970), Schmitz (1959) e Willey (1949).

Para não fugir da temática do artigo, passamos aos estudos mais recentes em que Bandeira (2004) identificou a técnica de confecção cerâmica nas vasilhas, coloração e tipo de pasta, acabamentos de superfícies, antiplástico, decoração plástica, formas das bordas e lábios, projeção de forma, elementos tradicionais na observação cerâmica desde o PRONAPA. Para a análise e interpretações do material cerâmico, Bandeira (2004) utilizou como referências Chymz (1966), Megger e Evans (1970), Shepard (1976), Miller Jr (1978), La Salvia e Brochado (1989), Rye (1981), Silva (1999), Wüst (1990) e Alves (1991).

No Programa de Pós-graduação em Geografia da UFSC, Fossari (2004) realizou um levantamento geral para grupos ceramistas na Ilha de Santa Catarina, analisando atributos tradicionais, como a identificação de partes das vasilhas, decoração, espessura dos fragmentos e formas da borda e da base.

Hansel (2004) produziu os primeiros resultados sobre a utilização de recipientes cerâmicos no processamento de derivados de animais marinhos, através de análises químicas de lipídios, citando os trabalhos de análise de cerâmica e a tradição vinculada aos Jê, além das referências tradicionais, como Chymz (1966).

Oliveira (2008) buscou demonstrar, a partir da decoração cerâmica, a normatização da tradição Tupiguarani, mas não apenas a sua rigidez, podendo ser performativa em determinadas ocasiões. De forma geral, a análise seguiu parâmetros histórico-culturais disponíveis para o momento e região, tendo como base os trabalhos de Brochado e Monticelli (1994) e La Salvia e Brochado (1989).

Milheira (2010) realizou a análise tecno-tipológica com foco na observação visual de atributos macroscópicos, tendo como objetivo a caracterização do modo de confecção das vasilhas Guarani e a compreesão dos aspectos formais. Os atributos principais da ficha de análise foram: a quantificação de fragmentos quanto à seção do pote; as variáveis métricas (espessura máxima, comprimento e largura); manufatura; antiplástico; tratamento de superfície externa e interna; e tipo de queima, utilizando como referências Shepard (1956), La Salvia e Brochado (1989) e Orton et al. (1997). Em seu trabalho, Milheira (2010) também utilizou dados etnográficos e etnohistóricos sobre a ocupação Guarani.

Carbonera (2015) analisou os vestígios cerâmicos dos sítios a partir da variabilidade tecno-estilística, incluindo atributos da pasta e dos tipos de queima. A autora também realizou análise macroscópica baseando-se em Alves (1988) e Chmyz (1976) e os atributos foram descritos a partir de Rice (1987), Sherpard (1956), Orton et al. (1997) e Rye (1981), com as reconstruções gráficas das vasilhas Guarani, utilizando como referencial os trabalhos de La Salvia e Brochado (1989) e Monticelli (1994).

Almeida (2017) utilizou os aspectos formais da cerâmica, como os processos de queima, a composição da pasta, o antiplástico, a decoração pintada, a forma e o tamanho das vasilhas para traçar um perfil tecno-tipológico, trabalhando com questões de variabilidade artefatual e estilo. Essa proposta baseou-se em Rye (1981), La Salvia e Brochado (1989), Brochado et al. (1990), Robrahn-González (1996) e Cerezer (2011).

O trabalho de Müller (2019) analisou as coleções cerâmicas a partir do viés tecnológico pautado sob as análises visuais (macroscópicas) e físico-químicas através da Fluorescência de Raios-X. A ficha de análise utilizada teve como principais referências La Salvia e Brochado (1989) e Machado (2005).

É interessante notar que os aspectos da ficha de análise para material cerâmico também foram partilhados por Ângela Salvador (2017), quando realizou a análise de material cerâmico histórico, utilizando como fonte autores como Chmyz (1976), La 
Salvia e Brochado (1989), Orton et al. (1997), Rice (1987), Zanettini (2005) e Moraes (2007), para suas inferências.

Por fim, enfatizamos que pesquisas geradas a partir de projetos que ainda estão em andamento, como o "Territorialidades Ameríndias no Alto Vale do Itajaí, Santa Catarina" coordenado pela Dra. Juliana Machado (MACHADO, 2019) e "Ceramistas Jê e Guarani na Baia Babitonga: cronologia e arqueometria regional" da Ms. Graciele Tules de Almeida (ALMEIDA et al., 2017), apresentam potencial para avançar nas análises de cerâmica no estado de Santa Catarina.

\section{DISCUSSÃO}

Diante das descrições apresentadas, nota-se que, na prática, a classificação das pesquisas e a construção de taxonomias culturais (ou descrições das tradições arqueológicas) mudaram pouco ao longo das últimas décadas. Riede et al. (2020) indicam que as taxonomias culturais estão em crise justamente pela falta fundamental de uma definição robusta dessas unidades taxonômicas analíticas que definem as culturas, as indústrias, as fácies, os grupos, as tradições, as fases, entre outros diante dos diversos métodos adotados para construir tais associações arqueológicas. Riede et al. (2020) apontam também que as questões taxonômicas e debates sobre as classificações mostraram um número substancial de tipos arqueológicos, que em muitos casos podem mais gerar confusão do que uma solução em relação às questões de padronização de atributos que possam dar conta da caracterização dos grupos humanos arqueologicamente representados.

Os trabalhos consultados para a escrita deste artigo, que totalizam 43 obras (entre teses, dissertações e artigos), puderam ser agrupados em quatro categorias (Tabela 1). Desse total, 34 apresentam análises tecnológicas, 28 análises tipológicas (sem que se atribua forma e função aos conjuntos analisados), 24 morfológicas (em que são identificadas as formas das vasilhas) e 15 estilísticas. A Tabela 2 apresenta os tipos de métodos complementares aplicados às análises cerâmicas e respectivos trabalhos associados a cada uma das categorias, seccionados por estado de origem. A classificação apresentada nas Tabelas 1 e 2, em quantidades e por atributos, vinculam-se diretamente à maneira como a forma que os próprios pesquisadores se auto identificaram em seus trabalhos. Por exemplo, pesquisas que prezaram por análises que enumeraram e descreveram os tipos de classe, as técnicas de manufatura, os tipos de antiplástico ou tempero e os tipos de queima, foram identificados como tipo de análise tecnológica. Os trabalhos que incluíram em suas análises aspectos relacionados à forma, seja das bases e das bordas (como a angulação, inclinação e espessura), dos lábios e contornos e diâmetros dos vasilhames, foram classificados enquanto tipo de análise morfológica. Por fim, os trabalhos que descreveram as áreas de aplicação e campos de grafismos, como as cores, os motivos, o engobo, a barbotina e o banho, foram classificados enquanto tipos de análises estilísticas. Ressaltamos que alguns trabalhos puderam ser encaixados em mais de uma dessas classes, conforme pode ser observado na Tabela 2. Todos e quaisquer trabalhos que apresentaram análises e abordagens complementares aos relatados anteriormente também foram descritos, como: análises espaciais e estatísticas; usos de conceituações trazidos pela Arqueologia da Paisagem, Geoarqueologia, Arqueologia da Persistência, Arqueometria e Arqueologia experimental; cadeia operatória; e identificações de números mínimos de vasilhas, bem como os usos de dados etnográficos, etnohistóricos, históricos, linguísticos e iconográficos; dados relativos às pesquisas museográficas; e funcionalidades das vasilhas foram apresentados pelos próprios autores das pesquisas e quantificados na Tabela 2. 
Tabela 1 - Tipos de análise cerâmica realizadas por estados. Elaboração dos autores (2020).

\begin{tabular}{cccccc}
\hline Estado & $\begin{array}{c}\text { Quantidade de } \\
\text { trabalhos }\end{array}$ & Tecnológica & Tipológica & Morfológica & Estilística \\
\hline São Paulo & 20 & 19 & 15 & 11 & 9 \\
\hline Paraná & 14 & 9 & 5 & 9 & 4 \\
\hline Santa Catarina & 9 & 6 & 8 & 4 & 2 \\
\hline Total & 43 & 34 & 28 & 24 & 15 \\
\hline
\end{tabular}

Tabela 2 - Análises e abordagens complementares aplicadas à cerâmica arqueológica nos estados. Elaboração dos autores (2020).

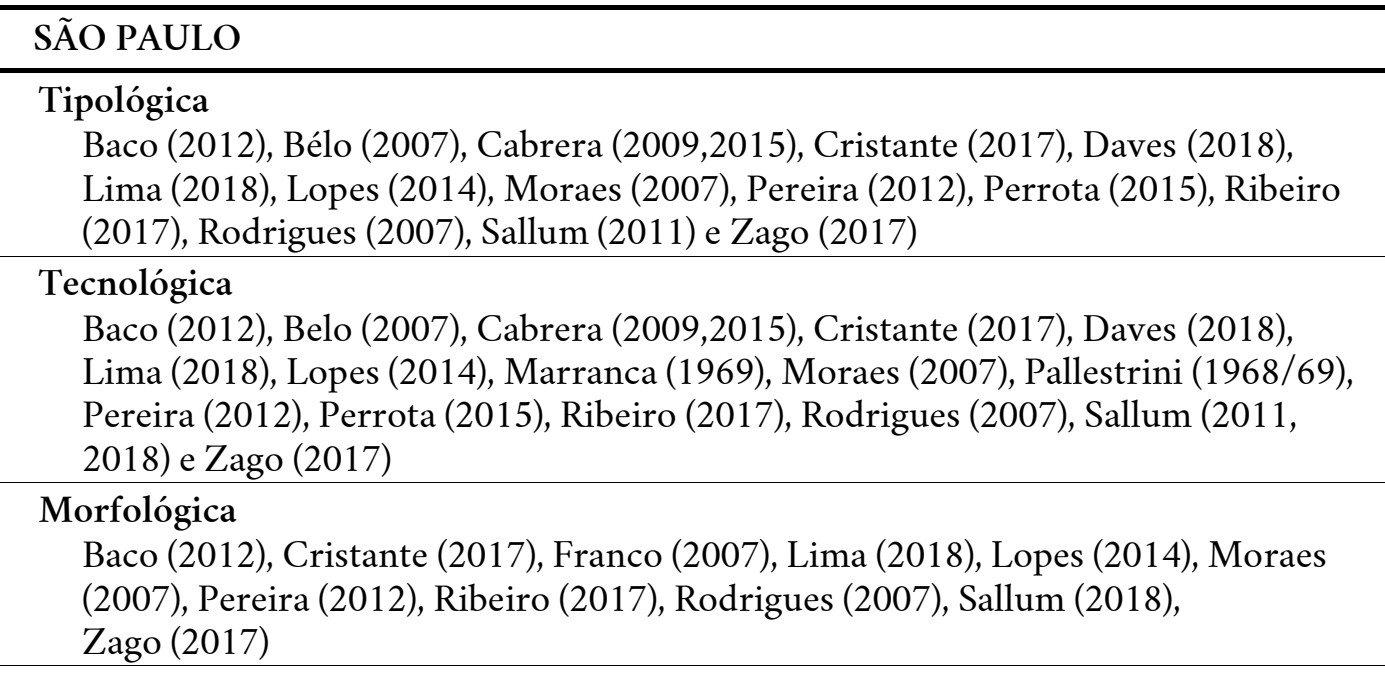
Estilística
Baco (2012, 2018), Cabrera (2009, 2015), Lopes (2014) Moraes (2007), Pereira (2012), Ribeiro (2017) e Zago (2017)

Análise espacial

Cabrera (2009, 2015), Cristante (2007), Lopes (2014), Sallum (2011)

\section{Análise estatística}

Franco (2007) e Perrota (2015)

Arqueologia da Paisagem e Geoarqueologia

Cabrera (2009), Daves (2018), Lima (2018), Zago (2017)

Arqueologia da Persistência

Sallum (2018)

Arqueometria

Bélo (2007) e Sallum (2011)

Cadeia operatória

Cabrera (2015)

Dados etnográficos, etnohistóricos, históricos, linguísticos e iconografia

Cristante (2017), Lopes (2014), Moraes (2007), Pallestrini (1968/1969),

Pereira (2012), Ribeiro (2017) e Rodrigues (2007)

Experimental

Baco (2012)

Pesquisa museográfica

Rodrigues (2007) e Ribeiro (2017) 


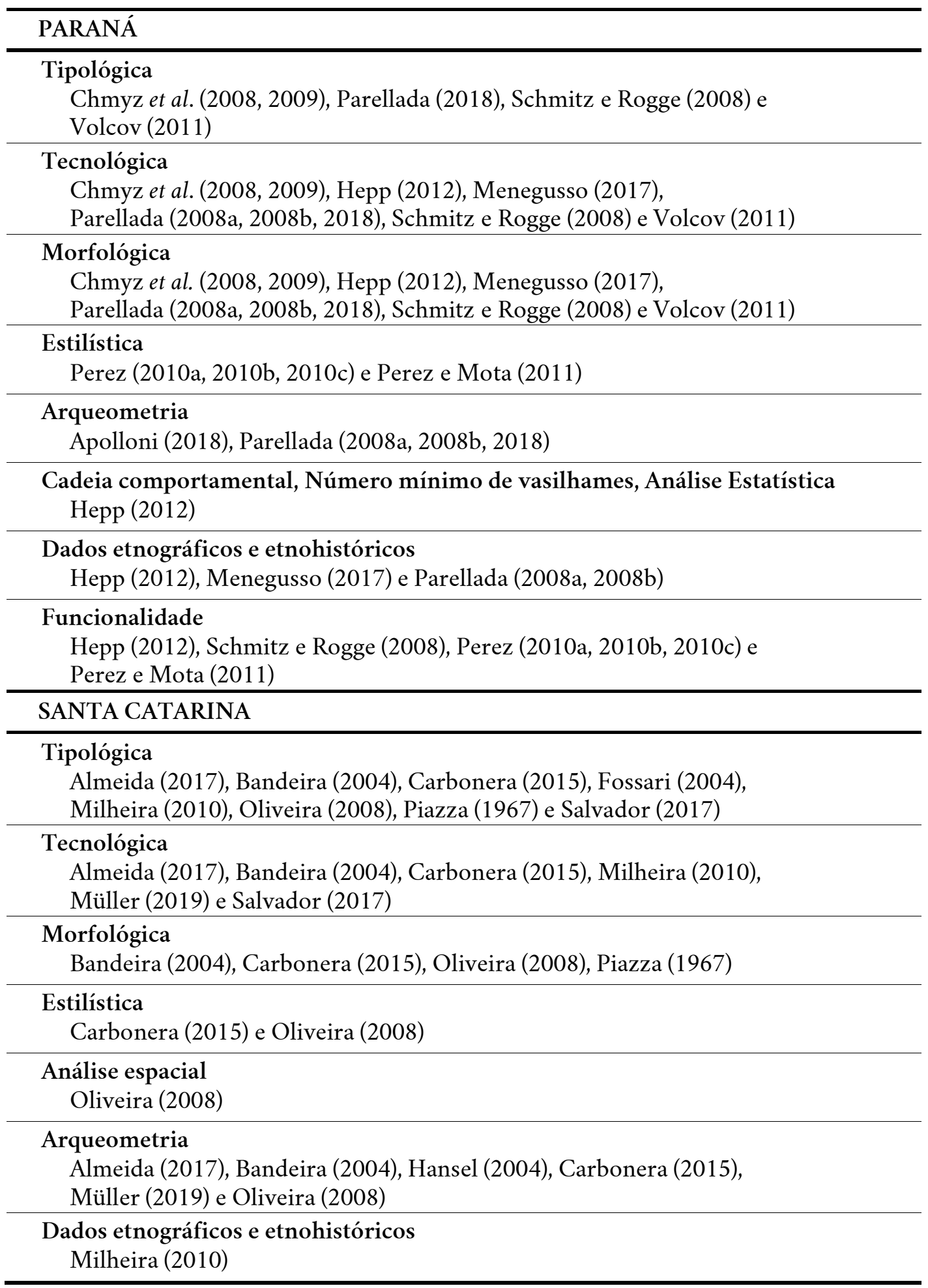

Observamos que os trabalhos utilizam roteiros de análise e de seleção de atributos muito próximos, variando parcialmente seu referencial teórico e de métodos complementares à análise. Assim, a preferência por uma linha teórica estaria atrelada à forma em que os dados são interpretados pelos autores diante de métodos e procedimentos semelhantes de análise.

Diante disso, qual seria a diferença em termos interpretativos ao adotar uma explicação que inclua a cadeia operatória ao invés da comportamental? Qual a relação entre teoria e método? As indagações apresentadas por Araujo (2019) e Riede et al. (2020) seriam pertinentes diante do que foi apresentado nesse trabalho de levantamento não 
exaustivo? Existiria algum tipo de influência direta sobre a maneira quase única de análise dos dados e suas interpretações?

Por fim, estamos discutindo se as questões práticas e os métodos elencados e utilizados pelos pesquisadores dão conta de descrever e sistematizar as informações que possam refletir a caracterização de grupos arqueologicamente reconhecidos através do seu suporte teórico e, nesse sentido, percebemos que o método de análise do material cerâmico segue por si só uma linha constante com pouca variabilidade na seleção dos atributos observáveis e descritos e a interpretação dos dados são muito semelhantes, apesar da adoção de corpos teóricos supostamente distintos. Questionamos se estamos diante de uma padronização de métodos de análises e também de uma homogeneização de resultados analíticos, sem que os pesquisadores se voltem para seu referencial teórico e percebam se sua forma analítica da cerâmica responde às questões investigadas e hipóteses propostas, e não apenas à ampliação e detalhamento das cadeias operatórias observadas.

\section{CONSIDERAÇÕES FINAIS}

Neste artigo buscamos evidenciar, a partir de um levantamento não exaustivo, os trabalhos que envolveram a análise de cerâmica realizadas nos estados de São Paulo, Paraná e Santa Catarina. Tal levantamento teve como intuito compreender como as análises cerâmicas foram realizadas, partindo da identificação dos métodos e atributos elencados para análise e vieses interpretativos. Nossa iniciativa vai ao encontro de percepções nacionais e internacionais que buscam a normatização e descrição dos motivos de atributos utilizados, mas sem perder de vista as particularidades de cada tipo de material arqueológico analisado e do referencial teórico dos diferentes autores. O que sugerimos é a observação dos diversos trabalhos de análise de material cerâmico pelo sul e sudeste brasileiro, para que possamos entender como é realizado tal processo de descrição dos atributos e seus referenciais teóricos.

Nossa observação dos trabalhos permitiu a identificação de diversas formas de caracterizações, mas que compõem uma colcha de retalhos de explicações e métodos para a variabilidade cerâmica regional. Cada trabalho pôde ser compreendido como um passo à frente para a interpretação e formulação de inferências para a espacialização desses grupos ceramistas no território.

É possível notar que existe uma iniciativa interdisciplinar, com a inclusão de disciplinas das áreas das ciências humanas, biológicas e exatas, para auxiliar na compreensão da cerâmica arqueológica, comprovando mais uma vez a interdisciplinaridade da arqueologia. Os métodos, por sua vez, têm sido adaptados para contextos específicos, porém não têm se alterado tanto como o discurso teórico.

Observou-se que o conceito de cadeia operatória é recorrente e que os métodos optados pelos autores, de separar os processos de produção da cerâmica por atributos variados, são independentes do referencial teórico utilizado para realizar as inferências explicativas dos conjuntos cerâmicos. Não foi observada a utilização do método de seriação dos fragmentos entre as teses, dissertações e artigos, em contraste com o que tem acontecido no exterior, como exemplo Bulbeck (2019), Downey (2017), Lulewicz (2019) e Torvinen e Nelson (2020).

Nota-se, ainda, que existem trabalhos que são continuamente citados durante as análises cerâmicas e poucas são as referências incorporadas da literatura internacional. Embora exista uma padronização em relação ao método, os autores não apresentam preocupação em estabelecer diálogo em um panorama mais amplo de análise do material cerâmico, para que se possa realizar comparações em escalas regionais. Apesar de muitas pesquisas serem comparativas entre diversos sítios, não há uma discussão dos atributos 
selecionados e das descrições realizadas em um contexto amplo e regional, verificandose muitas vezes que existe uma ampla descrição do que se foi analisado, sem, no entanto, aprofundar as escolhas culturais ou comportamentais em etapas de produção.

Apesar disso, as análises que envolvem métodos arqueométricos têm se destacado como importantes e complementares na construção de interpretações acerca dos vestígios e contextos inspecionados e acredita-se que tais métodos estejam auxiliando a provocar novos olhares para os vestígios arqueológicos.

De maneira breve, já que foge à intenção deste artigo, as observações em relação aos métodos arqueométricos são aplicadas desde a década de 1950, porém a conexão entre a arqueologia e as ciências exatas foi colocada em estado dormente, sendo retomada nos últimos anos com a atuação de alguns pesquisadores (rever Tabela 2). Cabe ressaltar ainda que essa retomada da arqueometria é uma opção de método para obter resultados mais detalhados em termos microscópicos, do que a pura quantificação e revisões macroscópicas dos conjuntos, e é factível que tais dados acrescentam informações nas interpretações das coleções cerâmicas.

Nesse sentido, o que pretendemos com este artigo é apresentar um levantamento sucinto dos trabalhos de arqueologia acadêmica que possam abrir um debate sobre como temos aplicado métodos de análise do material arqueológico e, obviamente, como avançar e superar questões teóricas para que possamos avançar em termos de interpretação e inferências mais acuradas para a ocupação pretérita, como sugerido por Corrêa (2014), Araujo (2019) e Riede et al. (2020). Este é o momento de uma reflexão sobre métodos de classificação dos atributos analisados, para que possamos normatizar tais atributos e construir um conjunto analítico que permita a comparação em escalas mais amplas.

\section{AGRADECIMENTOS}

Agradecemos aos autores que pesquisaram material cerâmico arqueológico nos últimos anos. Este trabalho jamais seria possível sem o trabalho minucioso e constante realizado ao longo do tempo. Pesquisas devem ser feitas, pois é a partir delas que conheceremos nossa história e construiremos nossa identidade social. Ao Professor LD Astolfo Gomes de Mello Araujo pela leitura atenciosa e reflexões sugeridas. À FAPESP pela bolsa de Doutorado de FTM (Processo 2017/08131-8). Ao CNPq pela bolsa PDJ de GCP (Processo 171000/2018-8) e bolsa de Doutorado de RPR (Processo 141750/20189). 


\section{REFERÊNCIAS BIBLIOGRÁFICAS}

ALMEIDA, Graciele Tules; BANDEIRA, Dione R. Ceramistas Jê e Guarani na Baia Babitonga: cronologia e arqueometria regional. Projeto de Pesquisa, Prêmio Elizabete Anderle, Joinville, 2017.

ALVES, Márcia Angelina. Análise cerâmica: estudo tecnotipológico. Tese (Doutorado em Arqueologia) - Museu de Arqueologia e Etnologia, , Universidade de São Paulo, São Paulo, 1988.

ALVES, Márcia Angelina. Culturas ceramistas de São Paulo e Minas Gerais - estudo tecnotipológico. Revista do Museu de Arqueologia e Etnologia, v. 1, n. 1, p. 71-96, 1991. DOI: https://doi.org/10.11606/issn.2448-1750.revmae.1991.107946.

APPOLONI, Carlos R. Estudos em arqueometria e arte por metodologias nuclear-atômicomoleculares não destrutivas no laboratório de física nuclear aplicada da Universidade Estadual de Londrina. Cadernos do Lepaarq, v. 30 n. 30, p. 219-228, 2018. DOI: https://doi.org/10.15210/lepaarq.v15i30.13011.

ARAUJO, Astolfo G. M. Por uma arqueologia cética: ontologia, epistemologia, teoria e prática da mais interdisciplinar das disciplinas. Curitiba: Editora Appris, 2019.

BACO, Hiuri M. Arqueologia Guarani e experimental no Baixo Paranapanema Paulista: o estudo dos sítios arqueológicos Lagoa Seca, Pernilongo, Aguinha e Rágil II. Dissertação (Mestrado em Arqueologia) - Museu de Arqueologia e Etnologia, Universidade de São Paulo, São Paulo, 2012. DOI: https://doi.org/10.11606/D.71.2012.tde-21062012-104518.

BACO, Hiuri M. A cerâmica pintada Guarani: o estudo dos desenhos presentes nas cerâmicas arqueológicas da área do Projeto Paranapanema. Tese (Doutorado em Arqueologia) - Museu de Arqueologia e Etnologia, Universidade de São Paulo, São Paulo, 2018. DOI: https://doi.org/10.11606/T.71.2018.tde-05062018-083915

BANDEIRA, Dione da Rocha. Ceramistas pré-coloniais da Baia da Babitonga, SC: Arqueologia e etnicidade. Tese (Doutorado em História) - Universidade Estadual de Campinas, Campinas, 2004. Disponível em: http://repositorio.unicamp.br/jspui/handle/REPOSIP/280839

BARRETO, Cristiana. Arqueologia brasileira: uma perspectiva histórica e comparada. Revista do Museu de Arqueologia e Etnologia, Suplemento 3, p. 201-212, 1999. DOI: https://doi.org/10.11606/issn.2594-5939.revmaesupl.1999.113468.

BÉLO, Taís P. Estudo tecnológico e das cadeias operatórias da cultura material lítica e cerâmica, coletada nos anos de 1995, 1996 e 2000, no sítio Água Limpa, município de Monte Alto, SP. Dissertação (Mestrado em Arqueologia) - Museu de Arqueologia e Etnologia, Universidade de São Paulo, São Paulo, 2007. DOI: https://doi.org/10.11606/D.71.2007.tde-06032008-142747.

BROCHADO, José P.; MONTICELLI, Gislaine; NEUMANN, E. S. Analogia etnográfica na reconstrução gráfica das vasilhas Guarani arqueológicas. Veritas, v. 35, n. 140, p. 727-743, 1990.

BROCHADO, José P.; MONTICELLI, Gislene. Regras práticas na reconstrução gráfica das vasilhas de cerâmica Guarani por comparação com vasilhas inteiras. Estudos Ibero-Americanos, v. 20, n. 2, p. 107-118, 1994.

BULBECK, David. Seriation Based on Agglomerative Clustering: An Example Using Ceramics Imported to Sulawesi, Indonesia. International Journal of Historical Archaeology, v. 24, p. 1-24, 2019. DOI: https://doi.org/10.1007/s10761-019-00516-9.

CABRERA, Jean Italo A. O sítio arqueológico Lagoa São Paulo - 02: uma análise Geoarqueológica de uma ocupação pré-histórica do oeste paulista. Dissertação (Mestrado em Geografia) Universidade Estadual Paulista, Presidente Prudente, 2009. Disponível em: http://hdl.handle.net/11449/89847.

CABRERA, Jean Italo A. O espaço ocupado pelo homem pré-histórico no oeste paulista: o caso do sítio arqueológico Lagoa São Paulo - 02 no município de Presidente Epitácio - SP. Tese (Doutorado em Geografia) - Universidade Estadual Paulista, Presidente Prudente, 2015. Disponível em: http://hdl.handle.net/11449/123857. 
CARBONERA, Mirian. A ocupação pré-colonial do alto Rio Uruguai, SC: contatos culturais na Volta do Uvá. Tese (Doutorado em Arqueologia) - Museu de Arqueologia e Etnologia, Universidade de São Paulo, São Paulo, 2015. DOI: https://doi.org/10.11606/T.71.2015.tde-07072015154149.

CEREZER, Jedson F. Cerâmica Guarani: Manual de experimentação arqueológica. Erechim: Habilis, 2011.

CHMYZ, Igor. Terminologia arqueológica brasileira para a cerâmica. Manuais de Arqueologia, CEPA-UFPR, n. 1, 1966.

CHMYZ, Igor. Terminologia arqueológica brasileira para a cerâmica: segunda edição, revisada e ampliada. Cadernos de Arqueologia, MAAP-UFPR, Paranaguá, v.1, p. 119-148, 1976.

CHMYZ, Igor; SGANZERLA, Eliane M.; VOLCOV, Jonas E.; BORA, Eloi; CECCON, Roseli S. A arqueologia da área da LT 750kV Ivaiporã-Itaberá III, Paraná-São Paulo. Arqueologia: Revista do Centro de Estudos e Pesquisas Arqueológicas, v. 5, p. 1-305, 2008.

CHMYZ, Igor; SGANZERLA, Eliane. M.; VOLCOV, Jonas E.; BORA, Eloi; CECCON, Roseli S. A arqueologia da área da Mina Dois Irmãos, em São Mateus do Sul, Paraná. Arqueologia: Revista do Centro de Estudos e Pesquisas Arqueológicas, v 6, p. 1-147, 2009.

CORRÊA, Ângelo A. Pindorama de Mboîa e Îakaré. Continuidade e Mudança na Trajetória das populações Tupi. Tese (Doutorado em Arqueologia) - Museu de Arqueologia e Etnologia, Universidade de São Paulo, São Paulo, 2014. DOI: https://doi.org/10.11606/T.71.2014.tde17102014-154640.

CRISTANTE, Mariane A. P. Práticas funerárias de Grupos de Linguas Tupi-Guarani: Análise de contextos das regiões do Paranapanema e Alto Paraná. Dissertação (Mestrado em Arqueologia) - Museu de Arqueologia e Etnologia, Universidade de São Paulo, São Paulo, 2007. DOI: https://doi.org/10.11606/D.71.2018.tde-01022018-103618.

DAVES, Larissa F. O estudo do sítio arqueológico Piracanjuba sob o enfoque da Arqueologia da Paisagem. Dissertação (Mestrado em Geografia) - Universidade Estadual Paulista, Presidente Prudente, 2018. Disponível em: http://hdl.handle.net/11449/157292.

DOWNEY, Jordan T. The Reliability of Using Surface Data for Seriation. Advances in Archaeological Practice, v. 5, n. 1, p. 26-43, 2017. DOI: https://doi.org/10.1017/aap.2016.2.

FACCIO, Neide Barrocá. Arqueologia dos cenários das ocupações horticultoras da Capivara, Baixo Paranapanema. Tese (Doutorado em Arqueologia) - Museu de Arqueologia e Etnologia, Universidade de São Paulo, São Paulo, 1998.

FACCIO, Neide Barrocá. Arqueologia Guarani na área do Projeto Paranapanema: estudo dos sítios de Iepê, SP. Tese (Livre Docência em Arqueologia) - Museu de Arqueologia e Etnologia, Universidade de São Paulo, São Paulo, 2011.

FRANCO, Célia. Visão sistêmica do sítio arqueológico Piracanjuba: a descoberta de conhecimento em sítios arqueológicos. Tese (Doutorado em Geografia) - Universidade Estadual Paulista, Presidente Prudente, 2007. Disponível em: http://hdl.handle.net/11449/100263.

FORD, James A. A quantitative method for deriving cultural chronology: Revised version of the working paper prepared for the Teaching Seminar in the Methods of Establishing Chronological Sequences of Pre-Columbian Cultures in the Americas, Barranquilla, Colombia, June 25-July 6, 1961. Washington, DC (EUA): Pan American Union, General Secretariat, Organization of American States, 1962.

FOSSARI, Teresa D. A população pré-colonial Jê na paisagem da Ilha de Santa Catarina. Tese (Doutorado em Geografia) - Universidade Federal de Santa Catarina, Florianópolis, 2004. Disponível em: http://repositorio.ufsc.br/xmlui/handle/123456789/87306

GALHARDO, Danilo A.; FACCIO, Neide B.; ROCHA LUZ, Juliana A. O conceito antropológico de cadeia operatória, sua aplicação e contribuição no estudo de instrumentos líticos 
arqueológicos. Cadernos do Lepaarq, v. 12, n. 23, p. 6-21, 2015 . DOI: https://doi.org/10.15210/lepaarq.v12i23.4113.

HANSEL, Fabrício Augusto. Arqueologia biomolecular: análise dos resíduos orgânicos preservados em ecofatos e artefatos recuperados de sítios arqueológicos costeiros pré-coloniais Jê - SC. Tese (Doutorado em Química) - Universidade Federal de Santa Catarina, Florianópolis, 2004. Disponível em: http://repositorio.ufsc.br/xmlui/handle/123456789/87960.

HEPP, Maurício. Estudo Arqueológico da ocupação Guarani no Vale do Rio Tibagi. Dissertação (Mestrado em Antropologia Social) - Universidade Federal do Paraná, Curitiba, 2012. Disponível em: https://hdl.handle.net/1884/29735

LA SALVIA, Fernando; BROCHADO, José Proença. Cerâmica Guarani. Porto Alegre/RS: Posenato Arte e Cultura, 1989.

LIMA, Paula Cabral. Paisagens testemunhos: um estudo geoarqueológico no norte do Estado de São Paulo. Dissertação (Mestrado em Geografia) - Universidade Estadual Paulista, Presidente Prudente, 2018. Disponível em: http://hdl.handle.net/11449/154308.

LIMA, Tânia Andrade. A teoria e método na Arqueologia Brasileira: Avaliação e Perspectivas. In: Souza, S. M. F. M de (org). Anais do $9^{\circ}$ Congresso da Sociedade de Arqueologia Brasileira. Rio de Janeiro: SAB, CD-ROM, 2000.

LOPES, Marcel. Ocupação Tupinambá no Vale do Paraíba Paulista: Vista a partir da análise do sítio arqueológico Santa Marina. 2014. Dissertação (Mestrado em Arqueologia) - Universidade de São Paulo, São Paulo. DOI: https://doi.org/10.11606/D.71.2014.tde-21032014-144952.

LULEWICZ, Jacob. A Bayesian approach to regional ceramic seriation and political history in the Southern Appalachian region (Northern Georgia) of the Southeastern United States. Journal of Archaeological Science, v. 105, p. 1-10, 2019. DOI: https://doi.org/10.1016/j.jas.2019.02.005.

MACHADO, Juliana Salles. Montículos Artificiais na Amazônia Central: um estudo de caso do sítio Hatahara. Dissertação (Mestrado em Arqueologia) - Museu de Arqueologia e Etnologia, Universidade de São Paulo, São Paulo, 2005.

MACHADO, Juliana Salles. Territorialidades Ameríndias no Alto Vale do Itajaí, Santa Catarina. Relatório I. Prêmio Elisabete Anderle 2017/FCC. Florianópolis/SC: Universidade Federal de Santa Catarina, 2019.

MARANCA, Silvia. Dados preliminares sobre a arqueologia do Estado de São Paulo. In: BROCHADO, José Proença; CALDERÓN, Valentin; CHIMZ, Igor; DIAS Jr., Ondemar; EVANS, Clifford; MARANCA, Sílvia; MEGGERS, Betty J.; MILLER, Eurico; PEROTA, Celso; PIAZZA, Walter; RAUTH, José; SIMÕES, Mário (org). Arqueologia Brasileira em 1968. Belém: Publicações avulsas do Museu Paraense Emilio Goeldi, v. 12, p. 133-139, 1969.

MARANCA, Silvia; SILVA, Andrea. L. M.; SCABELLO, Ana Maria. P. Projeto Oeste Paulista de arqueologia do Baixo e Médio Vale do rio Tietê: síntese dos trabalhos realizados. Revista do Museu de Arqueologia e Etnologia, v. 4, p. 223-226, 1994. DOI: https://doi.org/10.11606/issn.2448-1750.revmae.1994.109210.

MEGGERS, Betty J. A contribuição do Brasil à interpretação da linguagem da cerâmica. Arqueologia: Revista do Centro de Estudos e Pesquisas Arqueológicas, v. 4, p. 31-56, 2007.

MEGGERS, Betty J.; EVANS, Clifford. Como interpretar a linguagem da cerâmica: Manual para arqueólogos. Washington, DC (EUA): Smithsonian Institution, 1970.

MENEGUSSO, Maquieli E. Da cerâmica arqueológica Itararé-Taquara à cestaria Kaingang: um estudo a partir de uma perspectiva interdisciplinar sobre a trajetória Jê no baixo Tibagi, Paraná. Dissertação (Mestrado em História Social) - Universidade Estadual de Londrina, Londrina, 2017. Disponível em: http://www.bibliotecadigital.uel.br/document/?code=vtls000213675.

MILLER JR, Tom O. Tecnologia cerâmica dos Caingang paulistas. Arquivos do Museu Paranaense, Nova Série Etnologia, Curitiba, v. 2, p. 1-51, 1978. 
MILHEIRA, Rafael Guedes. Arqueologia Guarani no litoral sul-catarinense: história e território. Tese (Doutorado em Arqueologia) - Museu de Arqueologia e Etnologia, Universidade de São Paulo, São Paulo, 2010. DOI: https://doi.org/10.11606/T.71.2010.tde-23082010-161634.

MORAES, Camila. A. Arqueologia Tupi no nordeste de São Paulo: estudo da variabilidade artefatual. Dissertação (Mestrado em Arqueologia) - Museu de Arqueologia e Etnologia, Universidade de São Paulo, São Paulo, 2007. DOI: https://doi.org/10.11606/D.71.2007.tde-10072007-155042

MORAIS, José L. Projeto Paranapanema: Avaliação e Perspectivas. Revista de Antropologia, v. 24, p. 141-151, 1981.

MORAIS, José L.; FACCIO, Neide B.; PIEDADE, Silvia. Salvamento arqueológico da UHE Piraju ARQPIRAJU. Relatório técnico de Arqueologia Preventiva 1, 2 e 3, São Paulo, 2000.

MÜLLER, Isabela da Silva. Arqueologia Guarani no Litoral Central de Santa Catarina. Dissertação (Mestrado em Arqueologia) - - Museu de Arqueologia e Etnologia, Universidade de São Paulo, São Paulo, 2010. DOI: https://doi.org/10.11606/D.71.2019.tde-22072019-124139.

O'BRIEN, Michael J.; LYMAN, R. Lee. Applying evolutionary archaeology. A systematic approach. New York (New York/EUA): Klumer Academic Publishers, 2000.

OLIVEIRA, Kelly. Estudando a cerâmica pintada da Tradição Tupiguarani: a Coleção Itapiranga, Santa Catarina. Dissertação (Mestrado em História) - Pontifícia Universidade Católica do Rio Grande do Sul, Porto Alegre, 2008. Disponível em: http://hdl.handle.net/10923/3775.

ORTON, Clive; TYERS, Paul; VINCE, Alan. Pottery in Archaeology. Cambridge Manuals in Archaeology. Cambridge (Cambridgeshire/ENG): Cambridge University Press, 1997.

PALLESTRINI, Luciana. O sítio arqueológico Jango Luís. Revista do Museu Paulista, v. 18, p. 26$56,1968 / 1969$.

PARELLADA, Cláudia I. Tecnologia e estética da cerâmica Itararé-Taquara no Paraná: dados etno-históricos e o acervo do Museu Paranaense. Revista de Arqueologia, v. 21, n. 1, p. 97-111, 2008a. DOI: https://doi.org/10.24885/sab.v21i1.242.

PARELLADA, Cláudia I. Estética Indígena Jê no Paraná: tradição e mudança no acervo do Museu Paranaense. Revista Científica FAP, v.3, p. 213-229, 2008b. Disponível em: http://periodicos.unespar.edu.br/index.php/revistacientifica/article/view/1635.

PARELLADA, Cláudia I. A Cerâmica Guarani do Paraná, sul do Brasil: entrelaçando memória, tecnologia e arte. Anais do XV Congresso Nacional de Técnicas para as Artes do Fogo, Curitiba, Paraná, 2018. Disponível em: http://www.contaf.com.br/anais.

PEREIRA, David Lugli Turtera. Arqueologia Guarani na bacia do rio Santo Anastácio-SP: estudo do sítio Célia Maria. Dissertação (Mestrado em Arqueologia) - Museu de Arqueologia e Etnologia, Universidade de São Paulo, São Paulo, 2012. DOI: https://doi.org/10.11606/D.71.2012.tde16052012-135949.

PERROTA, Roberto M. Caracterização da indústria cerâmica do Sítio Bianco (Itapeva-SP): possíveis correlações culturais. Dissertação (Mestrado em Arqueologia) - Museu de Arqueologia e Etnologia, Universidade de São Paulo, São Paulo, 2015. DOI: https://doi.org/10.11606/D.71.2015.tde-19052015-153725.

PEREZ, Glauco C. Etnoarqueologia dos grafismos Guarani: estudo do acervo cerâmico do sítio arqueológico Córrego da Lagoa 2 - Altônia - PR. Dissertação (Mestrado em História) Universidade Estadual de Maringá, Maringá, 2010a.

PEREZ, Glauco C. A cultura guarani em debate: o Sítio Arqueológico Córrego da Lagoa 2. Revista de História da Arte e Arqueologia, v. 14, p. 39-55, 2010b.

PEREZ, Glauco C. Etnoarqueologia dos grafismos Guarani: estudo do acervo cerâmico do sítio arqueológico Córrego da Lagoa 2 - Altônia - PR. Diálogos,14(3): 669-672. 2010c. 
PEREZ, Glauco C.; MOTA, Lúcio T. O estudo do acervo cerâmico do Sítio Arqueológico Córrego da Lagoa 2, Altônia - Paraná: uma visão geral. Revista do Museu de Arqueologia e Etnologia, São Paulo, Suplemento 11, p. 115-118, 2011. DOI: https://doi.org/10.11606/issn.25945939.revmaesupl.2011.113544.

PIAZZA, Walter F. Nota preliminar sobre o Programa Nacional de Pesquisas Arqueológicas no Estado de Santa Catarina. Publicações Avulsas do Museu Paraense Emílio Goeldi. Resultados preliminares do primeiro ano 1965-1966. Belém: Museu Paraense Emílio Goeldi, p. 39-44, 1967.

RIBEIRO, Letícia. A'AngaEteMa - Imagens verdadeiras do passado: um estudo sobre a cerâmica Tupi pintada do interior paulista. Dissertação (Mestrado em Arqueologia) - Museu de Arqueologia e Etnologia, Universidade de São Paulo, , São Paulo, 2017. DOI: https://doi.org/10.11606/D.71.2018.tde-06022018-115356.

RICE, Prudence M. Pottery Analysis: A sourcebook. Chicago (Illinois/EUA): University of Chicago Press, 1987.

RIEDE, Felix; ARAUJO, Astolfo G. M.; BARTON, Michael C.; BERSVIK, Knut Andreas; GROUCUTT, Huw S.; HUSSAIN, Shumon T.; PABLO, Javier F. L. de; MAIER, Andreas; MARWICK, Ben. PYNNE, Lydia; RANHOM, Kattryn; REYNOLDS, Natasha; SALVATORE, Julien, R.; SAUER, Florian; SERWATKA, Kamil; ZANDER, Annabell. Cultural taxonomies in Paleolithic - old questions, novel perspectives. Evolutionary Anthropology, v. 29, p. 49-52, 2020. DOI: https://doi.org/10.1002/evan.21819

RYE, Owen S. Pottery Technology principles and reconstruction. Manuals on archaeology. Washington, DC (EUA): Taraxacum Inc, 1981.

ROBRAHN, Erika M. A ocupação pré-colonial do vale do Ribeira do Iguape, São Paulo: os grupos ceramistas do médio curso. Dissertação (Mestrado em Arqueologia) - Museu de Arqueologia, Universidade de São Paulo, São Paulo, 1989.

ROBRAHN-GONZÁLEZ, Erika. M. Os grupos ceramistas pré-coloniais do Brasil Central - Origens e Desenvolvimento. Tese (Doutorado em Arqueologia) - Museu de Arqueologia e Etnologia, Universidade de São Paulo, São Paulo, 1996.

ROBRAHN-GONZÁLEZ, Erika. M. Teoria e métodos na análise cerâmica em Arqueologia. Revista do Museu de Arqueologia e Etnologia, v. 8, p. 287-294, 1998. DOI: https://doi.org/10.11606/issn.2448-1750.revmae.1998.109555

RODRIGUES, Robson A. Os caçadores-ceramistas do sertão paulista: um estudo etnoarqueológico da ocupação Kaingang no vale do rio Feio/Aguapeí. Tese (Doutorado em Arqueologia) - Museu de Arqueologia e Etnologia,. Universidade de São Paulo, São Paulo, 2007. DOI: https://doi.org/10.11606/T.71.2007.tde-12092007-141110.

SALVADOR, Ângela Sabrine do Nascimento. Entre escritos e vasilhas cerâmicas: o indígena na sociedade colonial da Ilha de Santa Catarina (séculos XVIII e XIX). Dissertação (Mestrado em História) - Universidade Federal de Santa Catarina, . Florianópolis, 2017. Disponível em: https://repositorio.ufsc.br/xmlui/handle/123456789/180885

SALLUM, Marianne. Estudo do gesto em material cerâmico do sítio Gramado - município de Brotas, São Paulo. Dissertação (Mestrado em Arqueologia) - Museu de Arqueologia e Etnologia, Universidade de São Paulo, São Paulo, 2011. DOI: https://doi.org/10.11606/D.71.2011.tde18102011-084830.

SALLUM, Marianne. Colonialismo e Ocupação Tupiniquim no litoral sul de São Paulo: uma história de persistência e prática cerâmica. Tese (Doutorado em Arqueologia), - Museu de Arqueologia e Etnologia, Universidade de São Paulo, São Paulo, 2018. DOI: https://doi.org/10.11606/T.71.2019.tde-27092018-112906.

SCHIFFER, Michael. B. Archaeological Context and Systemic Context. American Antiquity, v. 37, n. 2, p. 156-165, 1972. DOI: https://doi.org/10.2307/278203. 
SCHIFFER, Michael; SKIBO, James. The explanation of artifact variability. American Antiquity, v. 62, p. 27-50, 1997. DOI: https://doi.org/10.2307/282378.

SCHMITZ, Pedro Ignácio. A cerâmica guarani da Ilha de Santa Catarina. Pesquisas, Antropologia, v.3, p. 267-324, 1959.

SCHMITZ, Pedro I.; ROGGE, Jairo H. Um sítio da tradição cerâmica Aratu em Apucarana, PR. Revista do Museu de Arqueologia e Etnologia, v. 18 p. 47-68, 2008. DOI: https://doi.org/10.11606/issn.2448-1750.revmae.2008.89828.

SILVA, Fabiola A. As cerâmicas dos Jê do sul do Brasil e os seus estilos tecnológicos: elementos para uma etnoarqueologia Kaingang e Xokleng. Revista do CEPA, v. 23, n. 30, p. 57-73, 1999

SILVA, Fabíola. A. Produção e uso da cultura material e a formação do registro arqueológico: o exemplo da cerâmica Asurini do Xingu. Revista do CEPA, v. 24, n. 32, p. 59-110, 2000.

SILVA, Fabíola Andréa. As tecnologias e seus significados: um estudo da cerâmica dos Asuriní do Xingu e da cestaria dos Kayapó-Xikrin sob uma perspectiva etnoarqueológica. Tese (Doutorado em Arqueologia) - Museu de Arqueologia e Etnologia, Universidade de São Paulo, São Paulo, 2000. DOI: https://doi.org/10.11606/T.8.2000.tde-03122013-165920.

SHEPARD, Anna O. Ceramics for the Archaeologist. Washington DC (EUA): Carnegie Institution of Washington, 1956.

TORVINEN, Andrea; NELSON, Ben A. Refinement of the Chronology of La Quemada, Zacatecas, Mexico, Using Ceramic Seriation. Latin American Antiquity, v. 31, n.1, p. 61-80, 2020. DOI: https://doi.org/10.1017/laq.2019.106.

VIDAL, Lux. Grafismos indígenas. São Paulo: Edusp, 1992.

VOLCOV, Jonas Elias. Cerâmica Tupiguarani e os processos de interação cultural no Alto Rio Iguaçu, PR. Dissertação (Mestrado em Antropologia) - Universidade Federal do Paraná, Curitiba, 2011. Disponível em: https://hdl.handle.net/1884/27058.

VOSS, Barbara L.; ALLEN, Rebecca. Guide to ceramic MNV calculation qualitative and quantitative analysis. Technical Briefs in Historical Archaeology, v. 5, p. 1-9, 2010. Disponível em: https://sha.org/assets/documents/Technical_briefs_articles/vol5article01.pdf

WICHERS, Camila Azevedo de Moraes. Patrimônio arqueológico paulista: proposições e provocações museológicas. Tese (Doutorado em Arqueologia) - Museu de Arqueologia e Etnologia, Universidade de São Paulo, São Paulo, 2012. DOI: https://doi.org/10.11606/T.71.2012.tde-19062012-133008.

WILLEY, Gordon Randolph. Excavations in southeast Florida. New Haven (Connecticut/EUA): Department of Anthropology, Yale University, 1949.

WÜST, Irmhild. Continuidade e Mudança - para uma interpretação dos grupos ceramistas précoloniais da bacia do rio Vermelho, Mato Grosso. Tese (Doutorado em Arqueologia) - Museu de Arqueologia e Etnologia, Universidade de São Paulo, São Paulo, 1990.

ZAGO, Juliana Aparecida Rocha L. Arqueologia da paisagem: estudo de sítios arqueológicos no norte do Estado de São Paulo. Tese (Doutorado em Geografia), Universidade Estadual Paulista, Presidente Prudente, 2017. Disponível em: http://hdl.handle.net/11449/149916.

ZANETTINI, Paulo Eduardo. Maloqueiros e seus palácios de barro: o cotidiano doméstico na Casa Bandeirista. Tese (Doutorado em Arqueologia) - Museu de Arqueologia e Etnologia, Universidade de São Paulo, São Paulo, 2005. DOI: https://doi.org/10.11606/T.71.2006.tde04082006-170833. 